\title{
Core curriculum guidelines for a required clinical neurology experience
}

\author{
Joseph E. Safdieh, MD, * Raghav Govindarajan, MD, * Douglas J. Gelb, MD, PhD, * Yazmin Odia, MD, and \\ Madhu Soni, MD
}

Neurology ${ }^{\circledR}$ 2019;92:619-626. doi:10.1212/WNL.0000000000007187

\section{Abstract}

Physicians in most specialties frequently encounter patients with neurologic conditions. For most non-neurologists, postgraduate neurologic education is variable and often limited, so every medical school's curriculum must include clinical learning experiences to ensure that all graduating medical students have the basic knowledge and skills required to care for patients with common neurologic symptoms and neurologic emergencies. In the nearly 20 years that have elapsed since the development of the initial American Academy of Neurology (AAN)endorsed core curriculum for neurology clerkships, many medical school curricula have evolved to include self-directed learning, shortened foundational coursework, earlier clinical experiences, and increased utilization of longitudinal clerkships. A workgroup of both the Undergraduate Education Subcommittee and Consortium of Neurology Clerkship Directors of the AAN was formed to update the prior curriculum to ensure that the content is current and the format is consistent with evolving medical school curricula. The updated curriculum document replaces the term clerkship with experience, to allow for its use in nontraditional curricular structures. Other changes include a more streamlined list of symptom complexes, provision of a list of recommended clinical encounters, and incorporation of midrotation feedback. The hope is that these additions will provide a helpful resource to curriculum leaders in meeting national accreditation standards. The curriculum also includes new learning objectives related to cognitive bias, diagnostic errors, implicit bias, care for a diverse patient population, public health impact of neurologic disorders, and the impact of socioeconomic and regulatory factors on access to diagnostic and therapeutic resources.

\author{
Correspondence \\ Dr. Safdieh \\ jos9046@med.cornell.edu
}

\section{RELATED ARTICLE}

\section{Editorial}

Teaching neurology:

Guided walk in the park or solo free-climb?

Page 599

\footnotetext{
*These authors contributed equally to this work.

From the Department of Neurology (J.E.S.), Weill Cornell Medicine/New York Presbyterian Hospital, NY; Department of Neurology (R.G.), University of Missouri, Columbia; Department of Neurology (D.J.G.), University of Michigan Medical School, Ann Arbor; Miami Cancer Institute (Y.O.), FL; and Department of Neurological Sciences (M.S.), Rush University Medical Center, Chicago, IL.

Go to Neurology.org/N for full disclosures. Funding information and disclosures deemed relevant by the authors, if any, are provided at the end of the article.

This article is endorsed by the American Academy of Neurology Undergraduate Education Subcommittee and the Consortium of Neurology Clerkship Directors.

The Article Processing Charge was funded by Weill Cornell Medicine.
}

This is an open access article distributed under the terms of the Creative Commons Attribution-NonCommercial-NoDerivatives License 4.0 (CC BY-NC-ND), which permits downloading and sharing the work provided it is properly cited. The work cannot be changed in any way or used commercially without permission from the journal. 


\section{Glossary}

DALY $=$ disability-adjusted life-year.

Neurologic disorders are common and are the leading cause of disability-adjusted life-years (DALYs), accounting for $10.2 \%$ of global DALYs and $16.8 \%$ of global deaths. ${ }^{1}$ Diseases of the nervous system accounted for $9 \%$ of the primary diagnoses at office visits in the United States in 2014, according to the National Ambulatory Medical Care Survey. ${ }^{2}$ Of the top 13 causes of DALYs in the United States in 2016, 6 (low back pain, Alzheimer disease, migraine, neck pain, ischemic stroke, and falls) are conditions that require the clinician to be able to perform and interpret a neurologic examination. ${ }^{3}$ Furthermore, projections suggest that due to aging of the American population, the number of US neurologists will be insufficient to provide care to this growing segment of patients. ${ }^{4}$

As a result, primary care and emergency physicians are-and will routinely be-called upon to evaluate and manage patients with neurologic disease. In addition, physicians in many other specialties need to recognize neurologic emergencies. Thus, physicians require a firm understanding of the general principles of clinical neurology. The most suitable setting in which to lay the foundation for that understanding is during the clinical phase of medical school.

Although a clinical neurology experience should be required of all medical students, the format of that experience may vary, depending on the organization of the overall curriculum at any given medical school. This document builds upon the $2002 \mathrm{Gelb}$ et al. ${ }^{5}$ neurology clerkship core curriculum and outlines the key components of a clinical neurology experience. The purpose is not to define the specific structure of that experience or to dictate mandatory content. Rather, this curriculum is intended to provide the principles underlying the required clinical neurology experience and its fundamental content, as well as the procedural and analytical skills that medical students, regardless of their ultimate field of practice, should master by the time they graduate from medical school.

\section{Goals and objectives of the clinical neurology experience}

\section{Definition of clinical neurology experience}

A clinical neurology experience provides medical students with the opportunity to learn how to care for patients with neurologic symptoms and disorders through practical contact and observation. The experience should be centered on direct patient care, and should also provide formal education sessions and assessments. While most medical schools still provide this experience in a traditional clerkship format, some have introduced nontraditional models such as multidisciplinary clerkships or longitudinal experiences. ${ }^{6}$ These curriculum guidelines apply to a clinical neurology experience of any type, whether a traditional clerkship or an innovative format.

\section{Goal}

To teach the principles and skills necessary to recognize and manage the neurologic diseases a general medical practitioner is most likely to encounter in practice.

\section{Objectives}

The goal of teaching students to recognize and manage neurologic disease encompasses 2 categories of objectives: the procedural skills necessary to gather clinical information and communicate it and the analytical skills needed to interpret that information and act on it.

1. To teach and reinforce proficiency in the following procedural skills:

a. Interviewing to obtain a complete and reliable neurologic history

b. Performing a reliable neurologic examination (table 1)

c. Examining patients with altered level of consciousness or abnormal mental status (table 2)

d. Delivering a clear, concise, and thorough oral presentation of a patient's neurologic history and examination

e. Preparing clear, concise, and thorough documentation of a patient's neurologic history and examination

f. Communicating empathetically with patients and families

g. [Ideally] Performing a lumbar puncture under direct supervision, or using simulation

2. To teach and reinforce proficiency in the following analytical skills:

a. Recognizing symptoms that may signify neurologic disease (including disturbances of consciousness, cognition, language, vision, hearing, equilibrium, motor function, somatic sensation, and autonomic function)

b. Identifying symptoms that may represent neurologic emergencies

c. Distinguishing normal from abnormal findings on a neurologic examination

d. Localizing the likely sites in the nervous system where a lesion may produce a patient's symptoms and signs

e. Formulating a differential diagnosis based on lesion localization, time course, and relevant historical and epidemiologic features

f. Explaining the indication, potential complications, and interpretation of common tests used in diagnosing neurologic disease 
Table 1 Guidelines for a comprehensive neurologic examination

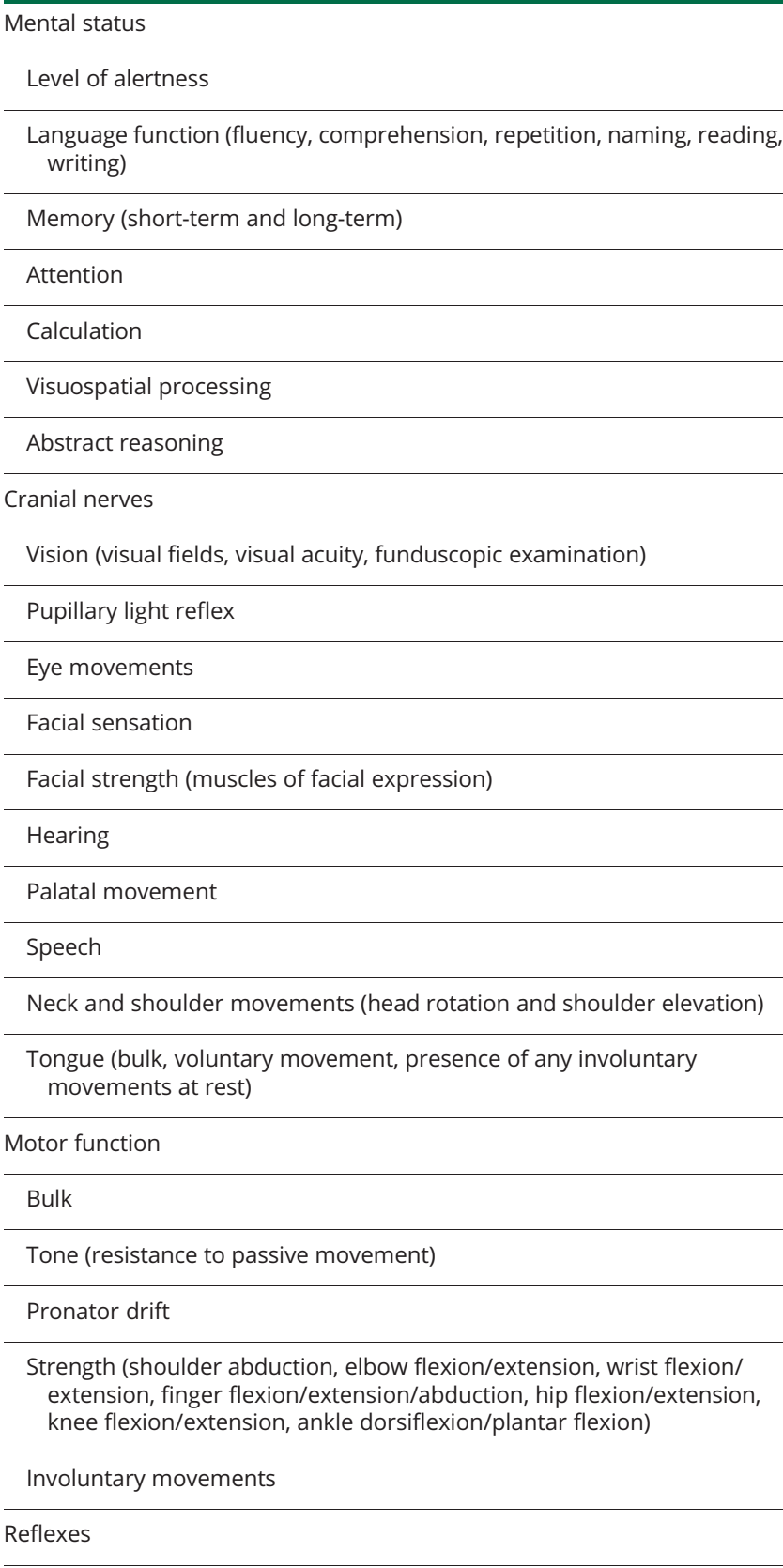

Deep tendon reflexes (biceps, triceps, brachioradialis, patellar, Achilles)

Plantar responses

Sensation

Light touch

Pain or temperature

Proprioception

Vibration

Romberg

Coordination

Fine finger movements
Table 1 Guidelines for a comprehensive neurologic examination (continued)

\begin{tabular}{l} 
Rapid alternating movements \\
\hline Finger-to-nose (or finger-to-chin) and heel-knee-shin \\
\hline Gait \\
\hline Casual \\
\hline Toes and heels \\
\hline Tandem
\end{tabular}

All medical students should be able to perform the outlined components of the neurologic examination. The emphasis should be on students acquiring the core examination skills required by any physician, rather than expecting specialized examination techniques that might be performed by a neurologist.

g. Demonstrating awareness of the principles underlying a systematic approach to the management of common neurologic diseases

h. Describing timely management of neurologic emergencies

i. Developing, presenting, and documenting a succinct, appropriate assessment and plan for the neurologic problem list

j. Recognizing situations in which it is appropriate to request neurologic consultation

k. Reviewing, interpreting, and applying pertinent medical literature to patient care

1. Understanding cognitive biases and their implications for diagnostic errors

m. Developing skills needed to deliver patient-centered, compassionate neurologic care with emphasis on diversity, inclusiveness, and recognition of implicit bias

n. Applying principles of medical ethics to patient care

o. Identifying socioeconomic and regulatory issues and other health disparities that may influence accessibility of affordable diagnostic and therapeutic resources

p. Explaining the public health impact of neurologic disorders

\section{Curriculum content}

Any complex topic can be organized in a variety of ways, and there is no perfect order in which to teach the topic. For example, the traditional preclerkship curriculum at many medical schools is organ-based and students learn the anatomy, physiology, histology, and pathophysiology of one organ followed sequentially by instruction on the other organs. Other medical schools employ a discipline-based preclerkship curriculum, in which students study anatomy of all organs throughout the body, followed by the physiology, histology, and so on. Each approach has its advantages and disadvantages. ${ }^{7,8}$

Similarly, neurology educators have traditionally advocated a variety of approaches to organizing topics when teaching clinical neurology. Some stress the primacy of the neurologic 
Table 2 Guidelines for the neurologic examination in patients with altered level of consciousness

\begin{tabular}{l}
\hline Mental status \\
\hline Level of arousal \\
\hline Response to auditory stimuli (including voice) \\
\hline Response to visual stimuli \\
\hline $\begin{array}{l}\text { Response to noxious stimuli (applied centrally and to each limb } \\
\text { individually) }\end{array}$ \\
\hline Cranial nerves \\
\hline Response to visual threat \\
\hline Pupillary light reflex \\
\hline Vestibulo-ocular reflex
\end{tabular}

a. In response to oculocephalic (doll's eyes) maneuver

b. In response to ice water caloric testing

Corneal reflex
Gag reflex

Respiratory drive (spontaneous, ventilator-assisted/controlled)

Motor function

Voluntary or purposeful movements

Reflex withdrawal

Spontaneous, involuntary movements

Tone (resistance to passive movement)

Reflexes

Deep tendon reflexes

Plantar responses

Sensation (to noxious stimuli in limbs)

examination and present clinical topics in the context of normal and abnormal examination findings. Others emphasize the importance of localization, and specifically the differentiation between focal and diffuse disease processes. Others maintain that the curriculum should center on a set of "scripts" for addressing a collection of common symptom complexes. Still others advocate pathophysiologic categories as the organizing principle. The following four sections represent alternative ways of organizing the same subject matter. Course directors may choose to emphasize some of these approaches more than others. The current curriculum guidelines are not meant to prescribe a particular way of presenting or organizing the material. However, all of the topics included in the following sections should be covered in some way.

\section{The neurologic examination}

As an integral component of the general medical examination:

1. Perform a pertinent, thorough neurologic examination (table 1)
2. Perform a screening neurologic examination sufficient for detecting major neurologic dysfunction in asymptomatic patients (table 3 )

3. Perform a neurologic examination on patients with an altered level of consciousness (table 2)

4. Know how to adapt the neurologic examination in young children (table 4)

5. Recognize and interpret abnormal findings on the neurologic examination

6. Demonstrate the use of techniques that ensure patient safety during the examination: some strategies include appropriate hand and instrument cleaning, single use of pins to test sensation, stabilizing position of the patient during muscle strength testing, and standing near the patient during the Romberg and gait examination

\section{Localization}

General principles differentiating lesions at the following levels:

1. Cerebral cortical and subcortical structures

2. Posterior fossa (brainstem and cerebellum)

3. Spinal cord

Table 3 Guidelines for a screening neurologic examination

Mental status (level of alertness, appropriateness of responses, orientation to date and place)

\begin{tabular}{l}
\hline Cranial nerves \\
\hline Visual acuity \\
\hline Pupillary light reflex \\
\hline Eye movements \\
\hline Hearing \\
\hline Facial strength (eye closure and smile) \\
\hline Speech \\
\hline Motor function \\
\hline Strength (shoulder abduction, elbow flexion/extension, wrist extension, \\
finger abduction, hip flexion, knee flexion/extension, ankle dorsiflexion) \\
Reflexes
\end{tabular}

Deep tendon reflexes (biceps, patellar, Achilles)

Plantar responses

Sensation (one modality at toes-can be light touch, pain, temperature, vibration, or proprioception)

Coordination (fine finger movements, finger-to-nose or finger-to-chin)

Gait (casual and tandem)

All medical students should be able to perform a brief screening neurologic examination that is sufficient to detect significant neurologic disease even in patients with no neurologic symptoms. Although the exact format of such a screening examination may vary, it should contain at least some assessment of mental status, cranial nerves, strength, reflexes, sensation, coordination, and gait. One example of a screening examination is given here. If there is reason to suspect neurologic disease based on the patient's history or the results of any components of the screening examination, a more complete examination is typically necessary. 
Table 4 Tips for performing challenging components of the neurologic examination in a child

\begin{tabular}{l}
\hline $\begin{array}{l}\text { Cranial nerves } \\
\text { Visual acuity: present toys of various sizes and colors and monitor } \\
\text { fixation/recognition }\end{array}$ \\
\hline $\begin{array}{l}\text { Visual fields: place a toy in the field of vision and note the location at which } \\
\text { the child turns to look towards the toy }\end{array}$ \\
\hline Eye movements: assess ocular movements to the sound of a bell or toy \\
\hline Hearing: monitor whether the child's head turns toward a bell sound on \\
each side \\
\hline Motor function: observe posture and simple maneuvers such as playing \\
with a ball or toy; observe for withdrawal to light bony pressure in the upper \\
and lower extremities \\
Reflexes: test primitive reflexes in infants, and know the ages when each \\
reflex is normally present \\
Sensation: observe for withdrawal to light bony pressure in the hands and \\
feet \\
\hline Coordination: assess how accurately the child reaches for and manipulates \\
toys
\end{tabular}

Performance of certain components of the neurologic examination may need to be adapted in children to assess function. This table provides some suggestions that may be helpful.

4. Anterior horn cell

5. Nerve root/plexus

6. Peripheral nerve (mononeuropathy, polyneuropathy, and mononeuropathy multiplex)

7. Neuromuscular junction

8. Muscle

\section{Symptom complexes}

A systematic approach to the evaluation and differential diagnosis of patients who present with:

1. Acute, subacute, or episodic changes in mental status or level of consciousness

2. Gradual cognitive decline

3. Aphasia

4. Headache or facial pain

5. Neck or back pain

6. Blurry vision or diplopia

7. Dizziness

8. Dysarthria or dysphagia

9. Weakness (focal or generalized)

10. Involuntary movements

11. Numbness, paresthesia, or neuropathic pain

12. Urinary or fecal incontinence/retention

13. Unsteadiness, gait disturbance, or falls

14. Sleep disorders

15. Delay or regression in developmental milestones

\section{Approach to specific conditions}

General principles for recognizing, evaluating, and managing the following neurologic conditions as important prototypes, or potentially disabling or life-threatening conditions:
1. Conditions that require prompt response

a. Acute stroke (ischemic or hemorrhagic) or TIA

b. Acute vision loss

c. Brain death

d. CNS infection

e. Encephalopathy (acute or subacute)

f. Guillain-Barré syndrome

g. Head trauma

h. Increased intracranial pressure

i. Neuromuscular respiratory failure

j. Spinal cord dysfunction

k. Status epilepticus

1. Subarachnoid hemorrhage

2. Alzheimer disease

3. Bell palsy

4. Carpal tunnel syndrome

5. Epilepsy

6. Essential tremor

7. Headache (tension, migraine, cluster)

8. Multiple sclerosis

9. Myasthenia gravis

10. Myopathy

11. Parkinson disease

12. Polyneuropathy

\section{Prerequisites for the trainee}

Successful completion of the foundational curriculum of medical school should be demonstrated, including clinically relevant neuroanatomy, neuropathophysiology, neuropharmacology, and physical diagnosis.

\section{Personnel needed for the training}

\section{Essential personnel}

1. Course director (preferably board-certified or boardeligible neurologist)

2. Additional full-time academic faculty

3. Administrative coordinator for the course director

Desirable personnel

1. Adjunct clinical faculty

2. Neurology house staff

3. Advanced practice providers

4. Neuroscience nurses

\section{Facilities needed for the training}

Clinical sites (primary institution or other) for both outpatient and inpatient care should be available with adequate time and space to permit patient evaluation, teaching sessions, and performance assessments.

\section{Methods of training}

As with curriculum content, there are various teaching formats, each with its own advantages and disadvantages. For 
example, educational experiences that revolve around actual patient contact have obvious relevance to the clinical issues students will encounter as practicing clinicians, but these experiences cannot be fully standardized. Simulated experiences, in contrast, can be standardized but they are inherently artificial. Patients who are "ideal" from the standpoint of having multiple abnormalities on neurologic examination may have rare neurologic diseases that are not immediately relevant to the types of conditions that most physicians will have to manage. There is no single ideal training format. The fundamental requirement is that at least some of the training must occur in the setting of actual patient care, under the supervision of teachers who specialize in neurology and who can apply the details of the individual patients to teach broader neurologic principles.

\section{Essential}

1. Required clinical encounters (appendix 1)

2. Supervised patient care encounters

3. Assessment of oral presentations and documentation

4. Teaching sessions

5. Material for independent study, including one or more of the following:
a. Locally generated syllabus
b. Published textbooks/references
c. Online resources

\section{Optional}

1. Formal lectures

2. Standardized patients

3. Simulation

\section{Timetable for training}

For adequate training, at least 4 weeks during the clinical phase of medical school is necessary. Ideally, students should be required to complete the neurology experience within the first 12 months of the clinical phase (e.g., in the traditional 4-year curriculum, a required, 4-week neurology experience in the third year is optimal).

\section{Methods of summative evaluation of the trainee}

Summative evaluation of medical student performance on clinical experiences should be multidimensional and at a minimum should include clinical performance evaluations and a knowledge assessment. Tools to evaluate students may include nationally written standardized examinations, locally developed examinations, locally developed clinical assessment forms with behavioral anchors based on learning objectives, bedside assessment evaluation forms, and oral presentation rubrics. ${ }^{6,9}$ The following list contains suggestions for various methods of evaluation.

\section{Clinical performance evaluations by the trainers assessing:}

1. Oral presentations and documentation

2. Fund of knowledge and clinical reasoning

3. Management skills and professionalism

4. Direct observation of the student interviewing and examining real patients or standardized patients

\section{Examinations including one or more of the following:}

1. Written

2. Online

3. Oral

4. Observed

\section{Projects/assignments incorporating one or more of the following:}

1. Self-directed learning

2. Evidence-based medicine

3. Graded history and physical

\section{Methods of evaluation of the training process}

In order to assess program effectiveness for departmental and institutional purposes, as well as for national accreditation, the clinical experience must be evaluated. This may be accomplished in several ways, which may be institutionspecific or based on nationally administered examinations or questionnaires.

A. Student performance on standardized examinations

B. Student evaluations of the trainers

C. Student evaluations of the training experience

\section{Mechanisms for formative feedback}

Formative feedback should be timely, frequent, specific, and constructive, focused on performance and not character. Methods include:

A. Informal, spontaneous verbal discussion

B. Scheduled session with supervisors

C. Formal midrotation email or in-person session highlighting strengths and areas for improvement; any student performing below expected level should receive in-person feedback

D. Written comments on performance (e.g., on written presentations, via feedback cards)

E. Verbal comments on oral presentations

\section{Faculty/resident orientation, instruction, and development}

Personnel engaged in supervising students must receive information about the clinical experience including the goals, 
Table 5 List of suggested clinical encounters

\begin{tabular}{|c|c|}
\hline Clinical presentation & $\begin{array}{l}\text { Encounter type (live } \\
\text { vs simulated) }\end{array}$ \\
\hline Transient neurologic event & Live \\
\hline \multicolumn{2}{|l|}{$\begin{array}{l}\text { Examples: abnormal involuntary } \\
\text { movement, dizziness, migraine aura, } \\
\text { seizure, sleep disorder, syncope, TIA }\end{array}$} \\
\hline Cognitive impairment, acute or chronic & Live \\
\hline \multicolumn{2}{|l|}{$\begin{array}{l}\text { Examples: acalculia, agnosia, altered } \\
\text { mental status, amnestic syndrome, } \\
\text { aphasia, apraxia, dementia, } \\
\text { developmental disability, dyslexia, } \\
\text { visuospatial dysfunction }\end{array}$} \\
\hline $\begin{array}{l}\text { Focal or diffuse motor disturbance, acute or } \\
\text { chronic }\end{array}$ & Live \\
\hline \multicolumn{2}{|l|}{$\begin{array}{l}\text { Examples: abnormal movement, ataxia, } \\
\text { diplopia, dysarthria, dysphagia, gait } \\
\text { impairment, urinary or fecal } \\
\text { incontinence, weakness }\end{array}$} \\
\hline Pain, acute or chronic & Live \\
\hline \multicolumn{2}{|l|}{$\begin{array}{l}\text { Examples: back pain, facial pain, } \\
\text { headache, neck pain, neuropathic pain, } \\
\text { thalamic pain }\end{array}$} \\
\hline $\begin{array}{l}\text { Sensory dysfunction (hypesthesia or } \\
\text { paresthesia) }\end{array}$ & Live \\
\hline
\end{tabular}

\begin{tabular}{l}
\hline $\begin{array}{l}\text { Examples: central causes of sensory } \\
\text { disturbance, neuropathy, plexopathy, } \\
\text { radiculopathy }\end{array}$ \\
\hline Neurologic emergencies \\
\hline Examples \\
\hline $\begin{array}{l}\text { a. Acute stroke (ischemic or } \\
\text { hemorrhagic) or TIA }\end{array}$ \\
\hline b. Acute vision loss \\
\hline c. Brain death \\
\hline d. CNS infection
\end{tabular}

e. Encephalopathy (acute or subacute)

f. Guillain-Barré syndrome

g. Head trauma

h. Increased intracranial pressure

i. Neuromuscular respiratory failure

j. Spinal cord dysfunction

k. Status epilepticus

Modified from Merlin LR, Horak HA, Milligan TA, et al. A competency-based longitudinal core curriculum in medical neuroscience. Neurology 2014;83: 456-462.11

objectives, and expectations, as well as information that will enhance their roles as teachers and evaluators.

A. Annual distribution of course goals, objectives, and curriculum to all teachers
B. Development and review of expectations for residents to be involved with teaching (residents as teachers)

C. Periodic faculty development activities

D. Regular (at least annual) review by course director of student evaluations for faculty and resident performance

E. Biannual or annual report of faculty and resident performance to chair and residency program director, respectively

Appendix 1. Required clinical encounters for neurology experiences

\section{Background}

The Liaison Committee on Medical Education (LCME) accreditation standards contain the following language:

The faculty of a medical school define the types of patients and clinical conditions that medical students are required to encounter, the skills to be performed by medical students, the appropriate clinical settings for these experiences, and the expected level of medical student responsibility. ${ }^{10}$

The LCME mandates that a system be established to specify the types of patients or clinical conditions that students must encounter and to monitor and verify the students' experiences with patients so as to remedy any identified gaps. The system, whether managed at the individual clerkship level or centrally, must ensure that all students have the required experiences. For example, if a student does not encounter patients with a particular clinical condition (e.g., because it is seasonal), the student should be able to remedy the gap by a simulated experience (such as standardized patient experiences or online or paper cases), or in another clerkship.

Recognizing that each medical school and clinical neurology experience will have individual needs and objectives, this resource is an American Academy of Neurology (AAN) recommendation. It provides support and guidance for required neurology clinical encounter standards that are reflective of the AAN Core Curriculum Guidelines for Required Clinical Neurology Experience. Table 5 contains types of clinical presentations listed in 6 categories. A specific patient may satisfy more than one presentation category. Clerkship directors, in consultation with their local curriculum committees, may select any or all encounters from this list and may select other clinical experiences that are not on this list if they meet local needs.

Original work group members: Tracey Milligan, MD (work group leader); David Geldmacher, MD; Richard Isaacson, BA, MD; Rama Gourineni, MD; Daniel Menkes, MD, FAAN; Imran Ali, MD; Amy Pruitt, MD; James Owens, MD, PhD; Nancy Poechmann (AAN staff).

Updated by Joseph E. Safdieh, MD, FAAN; Yazmin Odia, MD; Douglas Gelb, MD, PhD, FAAN; Raghav Govindarajan, MD, FAAN; Madhu Soni, MD, FAAN. 
Appendix Authors

\begin{tabular}{|c|c|c|c|}
\hline Name & Location & Role & Contribution \\
\hline $\begin{array}{l}\text { Joseph E. } \\
\text { Safdieh, MD, } \\
\text { FAAN }\end{array}$ & $\begin{array}{l}\text { Weill Cornell } \\
\text { Medicine/New } \\
\text { York Presbyterian } \\
\text { Hospital, New York }\end{array}$ & Author & $\begin{array}{l}\text { Manuscript concept } \\
\text { and design; drafted } \\
\text { the manuscript for } \\
\text { intellectual content }\end{array}$ \\
\hline $\begin{array}{l}\text { Raghav } \\
\text { Govindarajan, } \\
\text { MD, FAAN }\end{array}$ & $\begin{array}{l}\text { University of } \\
\text { Missouri, Columbia }\end{array}$ & Author & $\begin{array}{l}\text { Manuscript concept } \\
\text { and design; drafted } \\
\text { the manuscript for } \\
\text { intellectual content }\end{array}$ \\
\hline $\begin{array}{l}\text { Douglas J. } \\
\text { Gelb, MD, PhD, } \\
\text { FAAN }\end{array}$ & $\begin{array}{l}\text { University of } \\
\text { Michigan Medical } \\
\text { School, Ann Arbor }\end{array}$ & Author & $\begin{array}{l}\text { Manuscript concept } \\
\text { and design; drafted } \\
\text { the manuscript for } \\
\text { intellectual content }\end{array}$ \\
\hline $\begin{array}{l}\text { Yazmin Odia, } \\
\text { MD }\end{array}$ & $\begin{array}{l}\text { Miami Cancer } \\
\text { Institute, FL }\end{array}$ & Author & $\begin{array}{l}\text { Drafted the } \\
\text { manuscript for } \\
\text { intellectual content }\end{array}$ \\
\hline $\begin{array}{l}\text { Madhu Soni, } \\
\text { MD, FAAN }\end{array}$ & $\begin{array}{l}\text { Rush University } \\
\text { Medical Center, } \\
\text { Chicago, IL }\end{array}$ & Author & $\begin{array}{l}\text { Manuscript concept } \\
\text { and design; drafting; } \\
\text { critically revised the } \\
\text { manuscript for } \\
\text { intellectual content }\end{array}$ \\
\hline
\end{tabular}

\section{Acknowledgment}

The authors thank the AAN's Education Committee for manuscript review.

\section{Study funding}

No targeted funding reported.

\section{Disclosure}

J. Safdieh: royalties from Elsevier, editorial stipend from American Academy of Neurology. R. Govindarajan reports no disclosures relevant to the manuscript. D. Gelb: royalties from Oxford University Press, UpToDate, and Medlink Neurology, stipend from American Academy of Neurology. Y. Odia and $\mathrm{M}$. Soni report no disclosures relevant to the manuscript. Go to Neurology.org/N for full disclosures.

\section{Publication history}

Received by Neurology August 21, 2018. Accepted in final form December 31, 2018.

\section{References}

1. Feigin VL, Abajobir AA, Abate $\mathrm{KH}$, et al. Global, regional, and national burden of neurological disorders during 1990-2015: a systematic analysis for the Global Burden of Disease Study 2015. Lancet Neurol 2017;16:877-897.

2. National Ambulatory Medical Care Survey. 2015 State and national summary tables. Available at: cdc.gov/nchs/data/ahcd/namcs_summary/2015_namcs_web_tables. pdf. Accessed on February 28, 2018.

3. Murray CJL, Ballestros K, Echko M, the US Burden of Disease Collaborators. The state of US health, 1990-2016: burden of diseases, injuries, and risk factors among US states. JAMA 2018;319:1444-1472.

4. Dall T, Storm M, Charkrabarti R, et al. Supply and demand analysis of the current and future US neurology workforce. Neurology 2013;81:470-478.

5. Gelb DJ, Gunderson CH, Henry KA, et al. Consortium of neurology clerkship directors and the undergraduate education subcommittee of the American Academy of Neurology: the neurology clerkship core curriculum. Neurology 2002;58: 849-852.

6. Safdieh JE, Quick AD, Korb PJ, et al. A dozen years of evolution of neurology clerkships in the United States: looking up. Neurology 2018;91: e1440-e1447.

7. Brauer DG, Ferguson KJ. The integrated curriculum in medical education: AMEE Guide No. 96. Med Teach 2015;37:312-322.

8. Kulasegaram KM, Martimianakis MA, Mylopoulos M, et al. Cognition before curriculum: rethinking the integration of basic science and clinical learning. Acad Med 2013;88:1578-1585.

9. Stone RT, Mooney C, Wexler E, et al. Formal faculty observation and assessment of bedside skills for 3rd-year neurology clerks. Neurology 2016;21:10-212.

10. Liaison Committee on Medical Education. Functions and structure of a medical school. Available at: lcme.org/publications/\#Standards. Accessed August 20, 2018.

11. Merlin LR, Horak HA, Milligan TA, et al. A competency-based longitudinal core curriculum in medical neuroscience. Neurology 2014;83:456-462.

\section{Subspecialty Alerts by E-mail!}

Customize your online journal experience by signing up for e-mail alerts related to your subspecialty or area of interest. Access this free service by clicking on the "My Alerts" link on the home page. An extensive list of subspecialties, methods, and study design choices will be available for you to choose from-allowing you priority alerts to cutting-edge research in your field!

\section{Did You Know...}

... you can browse by subspecialty topics on Neurology.org?

Go to: Neurology.org and click on "Topics" in the top navigation bar. 


\section{Neurology}

\section{Core curriculum guidelines for a required clinical neurology experience \\ Joseph E. Safdieh, Raghav Govindarajan, Douglas J. Gelb, et al. \\ Neurology 2019;92;619-626 Published Online before print February 22, 2019 \\ DOI 10.1212/WNL.0000000000007187}

This information is current as of February 22, 2019

\section{Updated Information \& Services \\ References \\ Citations \\ Subspecialty Collections}

Errata

Permissions \& Licensing

Reprints including high resolution figures, can be found at: http://n.neurology.org/content/92/13/619.full

This article cites 9 articles, 4 of which you can access for free at: http://n.neurology.org/content/92/13/619.full\#ref-list-1

This article has been cited by 9 HighWire-hosted articles: http://n.neurology.org/content/92/13/619.full\#\#otherarticles

This article, along with others on similar topics, appears in the following collection(s):

\section{All Education}

http://n.neurology.org/cgi/collection/all_education

Methods of education

http://n.neurology.org/cgi/collection/methods_of_education

Other Education

http://n.neurology.org/cgi/collection/other_education

An erratum has been published regarding this article. Please see next page or:

/content/93/3/135.2.full.pdf

Information about reproducing this article in parts (figures,tables) or in its entirety can be found online at:

http://www.neurology.org/about/about_the_journal\#permissions

Information about ordering reprints can be found online:

http://n.neurology.org/subscribers/advertise

Neurology ${ }^{\circledR}$ is the official journal of the American Academy of Neurology. Published continuously since 1951, it is now a weekly with 48 issues per year. Copyright Copyright ( 2019 The Author(s). Published by Wolters Kluwer Health, Inc. on behalf of the American Academy of Neurology.. All rights reserved. Print ISSN: 0028-3878. Online ISSN: 1526-632X.

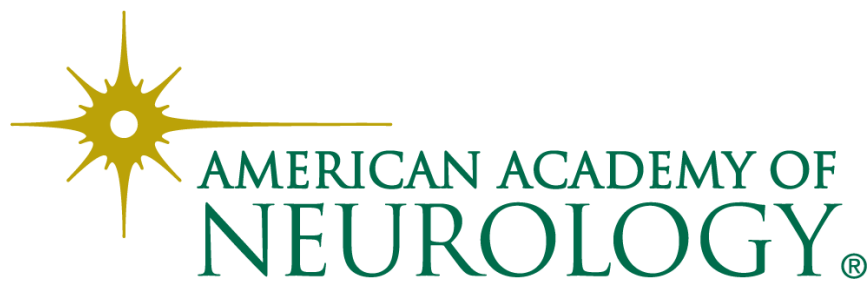




\title{
Disputes \& Debates: Editors' Choice
}

Steven Galetta, MD, FAAN, Section Editor

\section{Editors' note: Incorporating sleep medicine content into medical school through neuroscience core curricula}

In this issue of Neurology, Dr. Salas and a team of sleep medicine and medical education experts representing 6 major academic centers report on the need for and value of a formal sleep medicine curriculum in medical school. Not only are sleep medicine disorders extraordinarily common—affecting 1 in 6 Americans, according to survey data—but they are strongly tied to a swath of other comorbid conditions, ranging from cardiovascular disease to synucleinopathies. The authors also acknowledge that a heightened awareness of sleep hygiene among medical trainees may improve their own wellness and attenuate physician burnout. Dr. Sethi expresses some reservation that additional curricula may only add to the burden imposed upon medical students during their neurology clerkship. Instead, Dr. Sethi writes, perhaps sleep medicine should be incorporated into trainee education at the residency level. In response, Dr. Strowd and colleagues acknowledge this barrier. They emphasize the importance of pre-clerkship and longitudinal exposure to sleep medicine in order to crystallize these clinical concepts. By enriching the medical school curriculum with dedicated sleep medicine training, the authors hope that evaluating patients with sleep disorders will no longer be a sudden awakening.

\section{Reader response: Incorporating sleep medicine content into medical school through neuroscience core curricula}

\author{
Nitin K. Sethi (New York) \\ Neurology ${ }^{\circledR}$ 2019;93:132. doi:10.1212/WNL.0000000000007788
}

I read with interest the suggested proposal of Salas et al. ${ }^{1}$ to incorporate sleep medicine content into current medical school core curriculum. While I support the authors' recommendations, the medical school neuroscience core curriculum is already packed and students are burdened by a large number of specific learning objectives they are expected to meet by the end of their neurology clerkship. A better way to meet the growing need for sleep clinical care within the health care system would be to emphasize its education at the neurology residency level. The American Academy of Neurology Clinical Neurophysiology (CNP) Section Resident Core Curriculum $^{2}$ lists that the resident, "Be familiar with the basic principles of tests, including polysomnography, and multiple sleep latency tests, and evaluation of various sleep disorders.” In my experience, most neurology residents-during their CNP rotation-often spend time on CNP procedures, such as EEG and EMG, at the expense of sleep medicine.

1. Salas RME, Strowd RE, Ali I, et al. Incorporating sleep medicine content into medical school through neuroscience core curricula. Neurology 2018;91:597-610.

2. Westmoreland B. American Academy of Neurology Clinical Neurophysiology (CNP) Section Resident Core Curriculum. In: American Academy of Neurology: AAN Core Curricula [online]. Available at: aan.com/siteassets/home-page/tools-and-resources/academicneurologist-researchers/teaching-materials/aan-core-curricula-for-program-directorstor/clinical-neurophysiology-resident_tr.pdf. Accessed October 3, 2018.

Copyright (c) 2019 American Academy of Neurology 


\title{
Author response: Incorporating sleep medicine content into medical school through neuroscience core curricula
}

\author{
Roy E. Strowd (Winston-Salem, NC), Logan Schneider (Stanford, CA), Charlene E. Gamaldo (Baltimore), \\ and Rachel Marie E. Salas (Baltimore) \\ Neurology ${ }^{\circledR}$ 2019;93:133. doi:10.1212/WNL.0000000000007792
}

We appreciate Dr. Sethi's feedback highlighting some obstacles we considered when formulating our suggestions for integrating sleep medicine training into medical school, ${ }^{1}$ namely when and where to deliver sleep content.

We agree that more in-depth training should be provided to neurology residents, possibly as a component of their clinical neurophysiology rotations, as previously suggested. ${ }^{2}$ We also see a need for moving sleep medicine exposure earlier for all students. We agree that medical school curricula are already packed. We advocate for using evidence-based approaches that integrate clinical patient contact into preclerkship training and basic neuroscience instruction into clerkships. ${ }^{3,4}$ Preclerkship neuroscience courses should provide an entry point, teaching sleep fundamentals and providing exposure-which is currently the case of neuroscience curricula at some schools. Clerkship rotations then deepen students' application of sleep physiology to patients and focus on the clinical examination and management of sleep disorders.

Although we see neurology as an important leader in sleep medicine training, a strength of this field is the diversity of backgrounds that contribute to this area of medicine. Further integrating sleep training across these many fields during medical school and residency will likely reduce curricular burden, benefit training programs, and influence patients.

1. Salas RME, Strowd RE, Ali I, et al. Incorporating sleep medicine content into medical school through neuroscience core curricula. Neurology 2018;91:597-610.

2. Avidan AY, Vaughn BV, Silber MH. The current state of sleep medicine education in US neurology residency training programs: where do we go from here? J Clin Sleep Med 2013;9:281-286.

3. Wilkerson L, Stevens CM, Krasne S. No content without context: integrating basic, clinical, and social sciences in a pre-clerkship curriculum. Med Teach 2009;31:812-821.

4. Rajan SJ, Jacob TM, Sathyendra S. Vertical integration of basic science in final year of medical education. Int J Appl Basic Med Res 2016;6:182-185.

Copyright (c) 2019 American Academy of Neurology

\section{Editors' note: A sleep medicine medical school curriculum: Time for us to wake up}

In Dr. Smith's editorial regarding the newly suggested sleep medicine curriculum by Salas et al., the author summarizes a call to arms in order to increase trainee exposure to sleep disorders. For conditions that affect 50-70 million Americans, with tens of billions of dollars in annual healthcare costs, sleep medicine training comprises a regrettable minority of medical education $(0.06 \%$ of total classroom time). A heightened awareness of sleep disorders in medical school may also indirectly benefit medical students themselves as they reflect on their own sleep practices. With better sleep hygiene, Dr. Smith postulates, students may be at a lower risk of burnout. Dr. Spector, a sleep disorders specialist, worries that enforcement of additional coursework regarding sleep hygiene is hardly a solution to the burnout problem. Encouraging students to re-evaluate their own sleep practices by mandating additional coursework would be like "rubbing salt in a wound." Regardless of how or when formal instruction in sleep medicine is provided, everyone seems to agree that our deficiency of sleep medicine exposure should serve as a wake-up call for medical educators.

James E. Siegler III, MD, and Steven Galetta, MD

Neurology ${ }^{\circledR}$ 2019;93:133. doi:10.1212/WNL.0000000000007791 


\title{
Reader response: A sleep medicine medical school curriculum: Time for us to wake up
}

Andrew R. Spector (Durham, NC)

Neurology ${ }^{\circledR}$ 2019;93:134. doi:10.1212/WNL.0000000000007793

Dr. Smith is correct that there is an "urgent need to improve medical school sleep medicine education." I wholeheartedly agree with the proposal by Salas et al. ${ }^{2}$ Unfortunately, although there are many valid justifications for sleep medicine education, teaching about sleep will not improve burnout among medical students. The link between burnout and sleep is most likely due to sleep deprivation, ${ }^{3,4}$ but medical students are not sleep deprived because they lack the knowledge that they ought to sleep. Telling medical students to sleep more while providing no mechanism for them to do so is "rubbing salt in a wound." This could paradoxically worsen burnout by adding to the anxiety that they should be able to "do it all" - good grades, regular exercise, research, social life, and 8 hours of sleep. Sleep education will only improve students' well-being if it is coupled with substantial structural changes to the medical school experience that promote the health of the students (e.g., eliminating overnight call). Otherwise, we should promote sleep medicine education because it is important to being a well-educated physician and not because of any personal benefit for the students.

1. Smith AG. A sleep medicine medical school curriculum: time for us to wake up. Neurology 2018;91:587-588.

2. Salas RME, Strowd RE, Ali I, et al. Incorporating sleep medicine content into medical school through neuroscience core curricula. Neurology 2018;91:597-610.

3. Jarral OA, Baig K, Shetty K, Athanasiou T. Sleep deprivation leads to burnout and cardiothoracic surgeons have to deal with its consequences. Int J Cardiol 2015;179:70-72.

4. Leonard C, Fanning N, Attwood J, Buckley M. The effect of fatigue, sleep deprivation and onerous working hours on the physical and mental wellbeing of pre-registration house officers. Ir J Med Sci 1998;167:22-25.

Copyright (c) 2019 American Academy of Neurology

\section{Author response: A sleep medicine medical school curriculum: Time for us to wake up}

\author{
A. Gordon Smith (Richmond) \\ Neurology ${ }^{\circledR}$ 2019;93:134. doi:10.1212/WNL.0000000000007794
}

Dr. Spector raises an important point regarding sleep health and medical student wellness in response to my editorial. ${ }^{1}$ Addressing physician and medical student well-being will, indeed, require both structural and cultural changes in the practice of medicine. Neurology, as a specialty (largely through the efforts of the American Academy of Neurology), has established itself as a leader in addressing physician burnout. This level of professional advocacy is made possible by neurologists' recognition of this issue as a priority and their understanding of its drivers. Educating medical students about sleep health will not only prepare them to directly serve their patients' needs but will also equip them to care for themselves throughout their professional careers and to advocate for necessary reforms.

1. Smith AG. A sleep medicine medical school curriculum: time for us to wake up. Neurology 2018;91:587-588.

Copyright $\odot 2019$ American Academy of Neurology

Author disclosures are available upon request (journal@neurology.org). 


\section{Clinical phenotype, atrophy, and small vessel disease in APOE\&2 carriers with Alzheimer disease}

Neurology ${ }^{\circledR}$ 2019;93:135. doi:10.1212/WNL.0000000000007421

In the article "Clinical phenotype, atrophy, and small vessel disease in APOE\&2 carriers with Alzheimer disease" by Groot et al., ${ }^{1}$ published online ahead of print on October 19, 2018, there were errors in figure 1 and figure 5A. Figure 1 and figure 5A should each appear with axis labels. The corrected figures appear in the November 13 issue. The authors regret the error.

\section{Reference}

1. Groot C, Sudre CH, Barkhof F, et al. Clinical phenotype, atrophy, and small vessel disease in APOE\&2 carriers with Alzheimer disease. Neurology 2018;91:e1851-e1859.

\section{Core curriculum guidelines for a required clinical neurology experience}

Neurology ${ }^{\circledR}$ 2019;93:135. doi:10.1212/WNL.0000000000007481

In the article "Core curriculum guidelines for a required clinical neurology experience" by Safdieh et al., ${ }^{1}$ first published online February 22, 2019, the American Academy of Neurology Undergraduate Education Subcommittee and Consortium of Neurology Clerkship Directors should have been listed as endorsing the paper in a footnote and not listed in the author byline. The corrected version appears in the March 26 issue. The editorial office regrets the error.

\section{Reference}

1. Safdieh JE, Govindarajan R, Gelb DJ, Odia Y, Soni M. Core curriculum guidelines for a required clinical neurology experience. Neurology 2019;92:619-626.

\section{Practice guideline update recommendations summary: Disorders of consciousness}

Report of the Guideline Development, Dissemination, and Implementation Subcommittee of the American Academy of Neurology; the American Congress of Rehabilitation Medicine; and the National Institute on Disability, Independent Living, and Rehabilitation Research

Neurology ${ }^{\circledR} 2019 ; 93: 135$. doi:10.1212/WNL.0000000000007382

In the print version of the AAN Practice Guideline "Practice guideline update recommendations summary: Disorders of consciousness" by Giacino et al. ${ }^{1}$ published on September 4, 2018, the copyright line stating "Copyright (C) 2018 American Academy of Neurology" was included in error. The AAN does not claim copyright because the guideline was codeveloped by a US government agency. The corrected version was posted online on September 4, 2018. The publisher regrets the error.

\section{Reference}

1. Giacino JT, Katz DI, Schiff ND, et al. Practice guideline update recommendations summary: Disorders of consciousness: report of the Guideline Development, Dissemination, and Implementation Subcommittee of the American Academy of Neurology; the American Congress of Rehabilitation Medicine; and the National Institute on Disability, Independent Living, and Rehabilitation Research. Neurology 2018;91:450-460. 